\title{
CENTRO DE ESTUDOS VÊNETOS NO PARANÁ, CEVEP: HISTÓRICO E PRINCIPAIS AÇÕES EM PROL DA SALVAGUARDA DO TALIAN
}

\author{
Venetos Study Center in Paraná, CEVEP: History and Main Actions in \\ Favor of Talian Safeguard
}

Loremi LOREGIAN-PENKAL Universidade Estadual do Centro-Oeste, UNICENTRO

1lpenkal@unicentro.br https://orcid.org/0000-0002-1713-561X

Moisés Julierme STIVAL-SOARES Instituto do Patrimônio Histórico e Artístico Nacional, IPHAN moises.stival@iphan.gov.br https://orcid.org/0000-0002-3739-5275

RESUMO: Neste artigo, abordamos como se deu a formação do CEVEP, grupo de estudos que se constituiu em prol da salvaguarda do Talian falado no Paraná, de forma especial em Curitiba (Santa Felicidade) e região metropolitana (Colombo e Campo Largo). O grupo, com suporte teórico e metodológico da Sociolinguística (cf. WEINREICH; LABOV; HERZOG, 2006 [1968]; LABOV, 2008 [1972]), tem a participação ativa de representantes e detentores das comunidades italianas, o Museu Municipal Cristòforo Colombo, a Associazione Veneti nel Mondo, a UFPR, a Unicentro, a PUCPR e o IPHAN, órgão federal que reconheceu o Talian como referência cultural brasileira, por meio do Inventário Nacional da Diversidade Linguística. Entre as principais ações em andamento pela equipe do CEVEP pode-se destacar (i) a constituição do Banco de Dados do Talian; (ii) elaboração de glossários com registros das variedades de Talian faladas em cada comunidade pesquisada; (iii) elaboração de material didático em Talian; (iv) coleta e digitalização de material escrito de descendentes de italianos (vênetos); $(v)$ ações em prol da cooficialização do Talian no Paraná, entre outras. Neste texto, no entanto, vamos dar destaque ao item $(i)$ e demonstrar o estágio atual da coleta de entrevistas sociolinguísticas, nas três colônias vênetas acima citadas. PALAVRAS-CHAVE: CEVEP; Talian; língua de herança; Curitiba; região metropolitana.

ABSTRACT: In this paper, we approached the formation of CEVEP, a study group that was created to safeguard the Talian spoken in 
Paraná, especially in Curitiba (Santa Felicidade) and the metropolitan region (Colombo and Campo Largo). The group has a theoretical and methodological support from Sociolinguistics (WLH, 2006 [1968]; LABOV, 2008 [1972]). It has the active participation of representatives and descendants of Italian communities, the Cristòforo Colombo Municipal Museum, the Associazione Veneti nel Mondo, the UFPR, Unicentro, PUCPR and IPHAN, a federal agency that recognized the Talian as a Brazilian cultural reference, through the National Inventory of Linguistic Diversity. Among the main actions in progress by the CEVEP team are: $(i)$ the constitution of the Talian Database; (ii) elaboration of glossaries with records of Talian varieties spoken in each researched community; (iii) elaboration of didactic material in Talian; (iv) collection and digitization of written material from Italian descendants (Veneto); $(v)$ actions in favor of the co-officialization of Talian in Paraná, among others. In this text, however, we will highlight item $(i)$ and demonstrate the current stage of collecting sociolinguistic interviews, in the three Venetian colonies mentioned above. KEYWORDS: CEVEP; Talian; inheritance language; Curitiba; Metropolitan region.

RESUMO: In questo artìcolo, discoremo su la formassion del CEVEP, grupo de stùdii che el ze stà creà par la salvaguàrdia del Talian parlà ntel Paraná, in particolar in Curitiba (Santa Felicidade) e ntela region metropolitana (Colombo e Campo Largo). El grupo, con el suporto teòrico e metodològico dea Sociolengoìstica (cf. WEINREICH; LABOV; HERZOG, 2006 [1968]; LABOV, 2008 [1972]), el ga la partecipassion ativa de rapresentanti e detegnedori dee comunità italiane, el Museo Munissipal Cristòforo Colombo, Associassion Véneti nel Mondo, UFPR, Unicentro, PUCPR e IPHAN, ente federal che ga ricognossesto el Talian come Riferensa Cultural Brasiliana, par meso del Inventàrio Nassional dea Diversità Lengoìstica. In meso ale prinsipai assion podemo dir $(i)$ la costitussion del Banco de dati del Talian; (ii) la elaborassion de un glossàrio con registrassion dele varietà taliane parlae in ogni comunità esaminada; (iii) parciamento de material didàtico in Talian; (iv) racolta e digitalisassion de material scrito par i dissendenti de italiani (Véneto); $(v)$ assion in favor dela coofissialisassion del Talian ntel Paranà, tra altre. In questo testo, femo vedre el tòpico $(i)$ e anca dimonstremo la atual fase de interviste sossiolengoìstiche ntele tre colònie sora mensonade. PAROLECIAVE: CEVEP; Talian; léngoa de eredità; Curitiba; region metropolitana. 


\title{
PALAVRAS INICIAIS
}

No contexto linguístico brasileiro há uma diversidade de línguas e de culturas, muitas delas em contato entre si. O contato linguístico é uma das "fontes" de variação e de mudança nas línguas, características indispensáveis a todas as línguas vivas, pois as fazem se renovar constantemente. Podemos citar a língua portuguesa, de sinais, de imigrantes, de indígenas, de africanos, de refugiados, de fronteiras, maternas e estrangeiras.

Mengarda (2001) apresenta a questão da diversidade brasileira de uma forma bastante pertinente. $\mathrm{Na}$ visão deste pesquisador,

\begin{abstract}
Nos caracterizamos por uma multiplicidade de rostos, de gostos, de cores e de paisagens. Nossa trajetória histórico-cultural se inicia com o índio e se encontra com o desbravador português; culmina com a vinda dos negros, dos imigrantes europeus e asiáticos. Somos uma pluralidade de etnias, de línguas e de culturas. Se quisermos saber quem somos e entender nosso caráter comunitário, regional e/ou nacional estudemos nossas origens e as circunstâncias em que nossas comunidades foram sendo engendradas. Certamente, isto ajudará a redescobrir valores que paulatinamente correm o risco de serem esquecidos. (MENGARDA, 2001, p. 55).
\end{abstract}

Toda essa multiplicidade, a que Mengarda faz menção, nos identifica como sujeitos e nos torna o que somos. No entanto, como é sabido, nem sempre há a devida valorização e promoção dessa diversidade por parte do Estado brasileiro.

Na Região Metropolitana de Curitiba esse mosaico linguístico e cultural não é diferente, principalmente em Santa Felicidade (Curitiba), Colombo e Campo Largo, focos desta pesquisa, locais em que a presença de descendentes de imigrantes, especialmente de italianos, é expressiva e a forte influência da herança cultural e linguística de seus antepassados continua sendo evidenciada pelos seus falantes nos dias atuais (BALHANA, 1958; 1969). Prova disso é que nas três localidades citadas há organizações italianas diversas que promovem eventos e encontros culturais como, Festa da Uva, Festa do Vinho; Festa da Polenta; Settimana Italiana di Colombo, cursos e eventos relacionados à língua Talian, etc.

O Talian é uma das autodenominações para a língua de imigração/língua de herança ${ }^{1}$ falada no Brasil por descendentes de italianos e sua base linguística majoritária

\footnotetext{
${ }^{1}$ Após estudos e discussões de diversos autores que abordaram o tema, o grupo do CEVEP adotou a seguinte definição: "Língua de herança é a língua com a qual uma pessoa possui identificação cultural e sentimento de pertencimento a determinada comunidade que a usa, seja por laços
} 
é o Vêneto ${ }^{2}$, formada pelo contato linguístico com o português brasileiro, podendo haver também influências de dialetos setentrionais das regiões do Trentino-Alto Adige, FriuliVenezia Giulia, Piemonte, Lombardia, Emilia-Romagna e Ligúria (LUZZATTO, 1994).

Neste artigo, vamos apresentar o grupo de pesquisa Centro de Estudos Vênetos no Paraná, CEVEP e as principais ações já desenvolvidas e em andamento na região do Planalto Curitibano (Curitiba e Região Metropolitana), com destaque à coleta de entrevistas em Talian com falantes dessas comunidades.

Na Figura 01 apresentamos a localização das colônias italianas em que as pesquisas do CEVEP já estão em desenvolvimento.

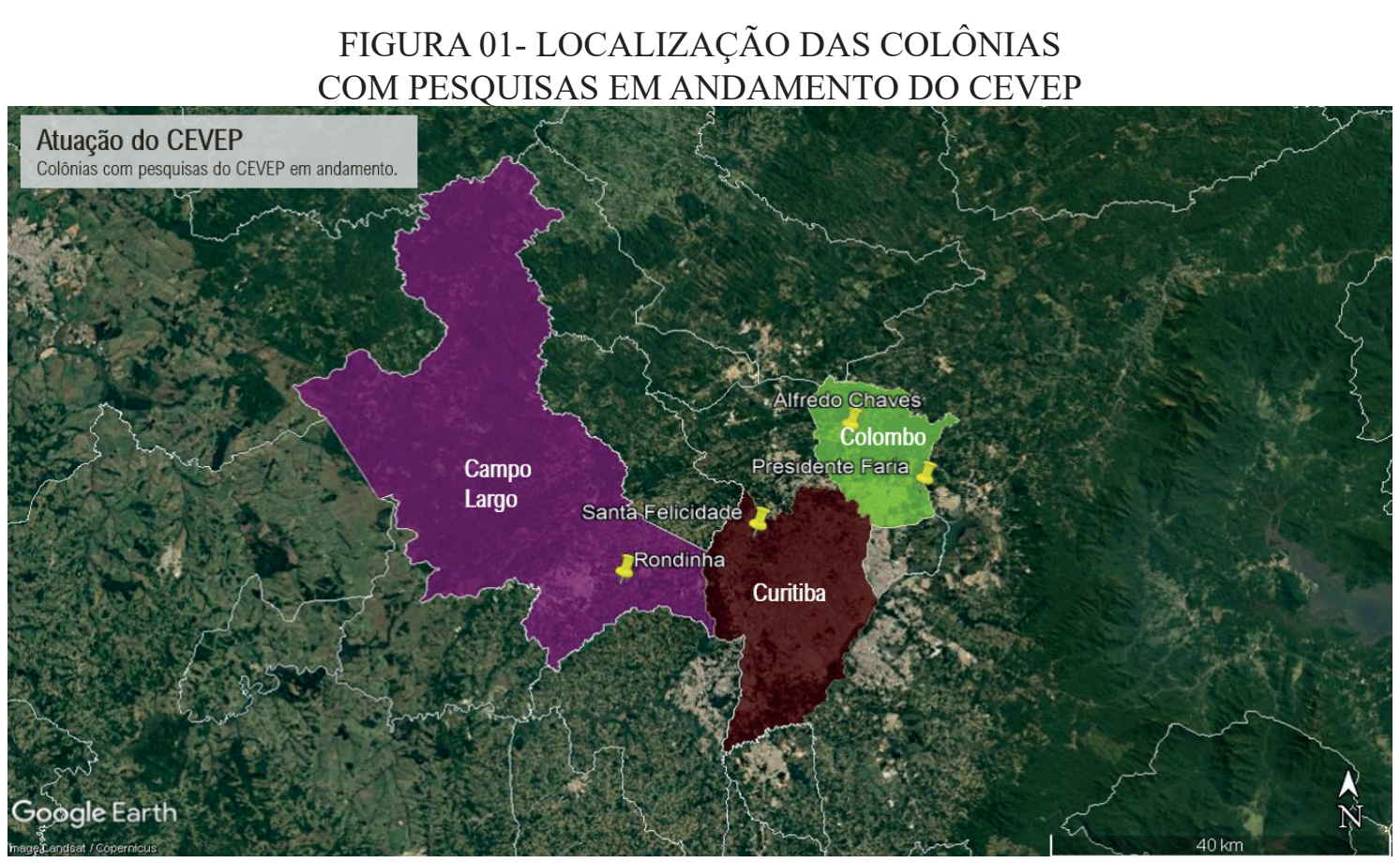

FONTE: base do Google Earth manipulada por STIVAL (2019).

Nota-se, portanto, que o bairro de Santa Felicidade, em Curitiba; a colônia Rondinha, em Campo Largo e as colônias de Alfredo Chaves e Presidente Faria, em

ancestrais, seja por convivência no mesmo ambiente sociocultural com falantes dessa língua." (ORTALE, 2016, p. 27). A questão de o Talian ser considerado uma língua de herança nas comunidades pesquisadas foi uma temática bastante discutida pelo grupo que, após ouvir alguns falantes/detentores da língua, passou a adotar esta denominação.

${ }^{2} \mathrm{O}$ Vêneto ou Língua Vêneta é um conjunto de dialetos falados em uma porção da região nordeste da Itália. Segundo Ursini (2011), na Região do Vêneto há quatro macro principais variedades: Veneziano; Veneto centrale (padovano-vicentino-polesano); Veneto occidentale (veronese); Veneto settentrionale (trevigiano-feltrino-bellunese). 
Colombo, compõem o estágio inicial das pesquisas e ações do CEVEP.

Criado em 2018, o CEVEP agrega pesquisadores de universidades públicas e privadas do Paraná, membros de associações ligadas à promoção cultural e integrantes/ detentores do Talian membros das comunidades pesquisadas. O grupo visa atuar no registro, descrição, valorização, divulgação e difusão do Talian, língua da imigração italiana/de herança formada no contexto nacional, reconhecida como Referência Cultural Brasileira em 2014 pelo IPHAN e pelo Ministério da Cultura, por meio do Inventário Nacional da Diversidade Linguística, INDL (2010).

\section{PERFIL DAS COMUNIDADES PESQUISADAS: SANTA FELICIDADE, CO- LOMBO E CAMPO LARGO}

As comunidades do bairro de Santa Felicidade, em Curitiba, e dos municípios de Colombo e Campo Largo, estudadas nesta pesquisa, constituem uma significativa parcela da Região de Colonização Italiana do Paraná (RCI/PR). Além desses municípios, constituem a região de imigração os municípios paranaenses de Almirante Tamandaré, Bocaiúva, Campina Grande do Sul, Cerro Azul, Imbituva, Lapa, Morretes, Palmeira, Paranaguá, Piraquara, Quatro Barras e São José dos Pinhais. Esses municípios formam a região de imigração italiana direta do estado do Paraná. ${ }^{3}$

As primeiras famílias italianas que chegaram à então Província do Paraná se estabeleceram inicialmente na Colônia Assungui, no atual município de Cerro Azul, em 1860. No entanto, é a partir da década de 1870 que o Paraná passa a receber maior número de imigrantes, pois o governo provincial passou a adotar um plano de assentamento de colonos estrangeiros (alemães, poloneses, italianos, ucranianos, etc) em núcleos agrícolas nas proximidades da capital paranaense. O objetivo do plano era de atrair mão de obra para a produção agrícola para abastecer os centros urbanos; inserir o imigrante europeu no processo de ocupação do território, bem como promover o branqueamento da população brasileira.

Os primeiros núcleos coloniais voltados para receber italianos foram criados pelo Governo Provincial no litoral do Paraná, nos municípios de Paranaguá e Morretes, entre 1875 e 1877 (Alexandra e Nova Itália, respectivamente). As colônias do litoral não

\footnotetext{
${ }^{3}$ A região leste do Paraná é a região de colonização italiana do estado caracterizada pela imigração direta. No entanto, esclarecemos que há outras áreas de imigração italiana no Paraná caracterizadas, porém, pela imigração indireta. Ou seja, os imigrantes e descendentes de italianos provinham de outros estados brasileiros, como é o caso das regiões sudoeste, oeste e do norte do Paraná.
} 
chegaram a prosperar por uma série de motivos que geraram um clima de instabilidade e a consequente revolta dos imigrantes. Dentre esses motivos citamos o atraso na medição e divisão dos lotes, a falta de estradas que interligasse os núcleos coloniais, a má distribuição de alimentação e a falta de condições de higiene. Diante dessa crise, muitas das famílias ali instaladas se deslocaram em direção ao planalto curitibano a partir de 1878. (MACHIOSKI, 2018)

No planalto curitibano, a instalação dos imigrantes italianos se deu de modo variado. Parte das famílias permaneceram em Curitiba, no centro urbano. Eram comerciantes, profissionais liberais e industriais. Já, ao redor da urbe, foram criadas as colônias agrícolas de Santa Maria do Novo Tirol (em Piraquara) - formada inicialmente por imigrantes trentinos - , Alfredo Chaves (em Colombo), Senador Dantas (hoje bairro Água Verde de Curitiba), Santa Felicidade (em Curitiba) e Antonio Rebouças (em Campo Largo), essas formadas sobretudo por imigrantes vênetos. Além desses núcleos, algumas colônias mistas receberam italianos nessa época: Orleans e Argelina (em Curitiba); Murici, Inspetor Carvalho e Zacarias (em São José dos Pinhais). (MACHIOSKI, 2018)

Entre 1870 e 1890, segundo o historiador Romário Martins (1995), havia um total de vinte núcleos coloniais de italianos. Além das colônias citadas anteriormente, até o final do século XIX, havia na região de Curitiba os núcleos de: Balbino Cunha, Mariana, Timbotuva, Ferraria e Rondinha (Campo Largo); Campo Comprido, Umbará (Curitiba); Gabriela (Almirante Tamandaré); Antonio Prado, Capivari e Faria (Colombo); e Acioli (São José dos Pinhais).

Na Figura 02 vemos as colônias italianas na capital paranaense e nos seus arredores até o final do século XIX. Nessa época, do ponto de vista religioso, todas as colônias eram atendidas pela Capelania de Santa Felicidade. 


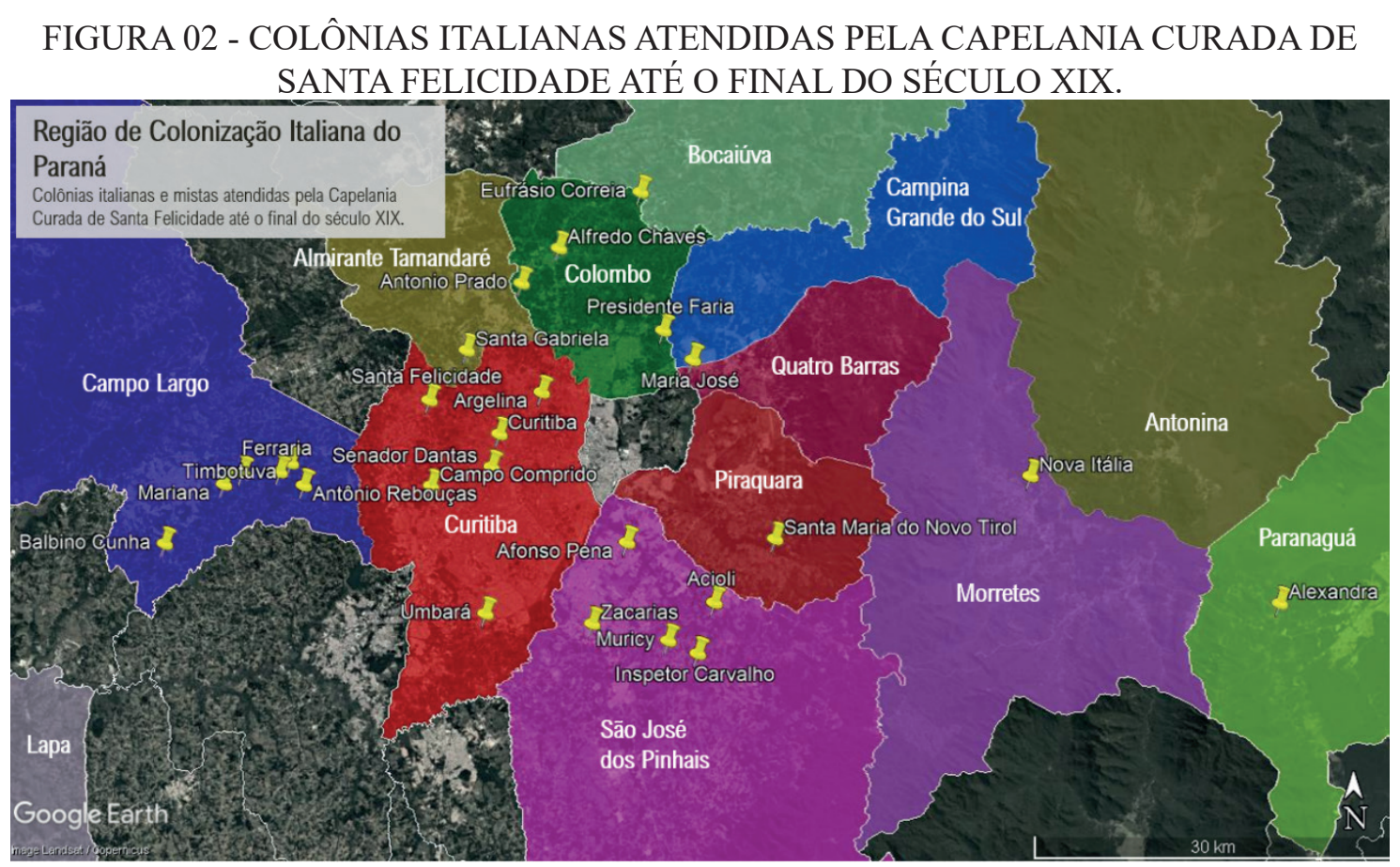

FONTE: base do Google Earth manipulada por STIVAL (2019).

Nota-se que a Capelania de Santa Felicidade atendia a um número vasto de colônias, fato que denota a religiosidade extrema dos descendentes de italianos, bem como a escassez de padres para atender à vasta demanda de fiéis.

Em relação à origem dos imigrantes, Balhana (1978) aponta que em pesquisa realizada junto às atas matrimoniais dos imigrantes da colônia de Santa Felicidade, em Curitiba, verificou-se que a maioria dos colonos italianos eram oriundos da diocese de Vicenza, na região do Vêneto. Seguiam-se em ordem decrescente os imigrantes oriundos de Padova, Treviso, Verona, Cremona, Belluno, Ceneda (atualmente Vittorio Veneto), Udine, Feltre e Venezia. ${ }^{4}$ Portanto, a grande maioria era oriunda do Vêneto.

Em Campo Largo, Scarpim (2010) constatou também por meio dos registros de matrimônio que cerca de $95 \%$ dos imigrantes provinham do Vêneto, sobretudo das províncias de Vicenza e Treviso. Em Colombo, Machioski (2004) concluiu que a representatividade dos imigrantes vênetos era de 93\%, especialmente vicentinos e trevisanos.

Desse modo, percebemos com os dados das colônias dos municípios de Campo

\footnotetext{
${ }^{4}$ Segundo Balhana (1978), as atas evidenciam que havia grupos originários de Lupari (San Martino di Lupari), Rosà, Dueville, Grômolo (Grumulo), Sandrigo, Pozzanella (Poianella di Bressanvido), San Nazario, Tezze (sul Brenta), Brusaporco, Godego (Castello di Godego), Valstagno (Valstagna) e outras. Todos esses comunes situam-se no Vêneto, nas províncias de Vicenza, Treviso e Padova.
} 
Largo e Colombo, e do bairro de Santa Felicidade, em Curitiba, que estas eram formadas por imigrantes provenientes, sobretudo, do Vêneto, em particular das províncias de Vicenza e Treviso. ${ }^{5}$

A presença vêneta é também identificada por Balhana (1958) na língua falada pelos imigrantes e descendentes de italianos da colônia de Santa Felicidade, durante a sua pesquisa na década de 1950. Em seu livro Santa Felicidade: um processo de assimilação a autora apresenta um glossário de aproximadamente 500 lexias na língua local. Segundo Balhana, a língua falada tinha como origem o dialeto vêneto, porém já apresentava elementos oriundos do contato com a cultura brasileira:

a maioria pertence ao vocabulário do dialeto vêneto, porém outras representam já a evolução da linguagem tradicional dos colonos de Santa Felicidade em contacto com outro meio e outra cultura. Há mesmo muitas expressões novas, neologismos criados em função das novas condições ambientais. (BALHANA, 1958, p. 259).

Considerando, portanto, a origem dos imigrantes, o glossário de Balhana e os estudos em andamento pelo CEVEP, entendemos que na Região de Colonização Italiana do Paraná, o Talian falado se trata de uma coiné de base vêneta, especialmente do vicentino e trevisano em contato entre si e com o português do Brasil, com características próprias, derivadas do contexto brasileiro, que a diferem da matriz original.

Nas colônias pesquisadas, a língua é denominada, frequentemente, pelos seus falantes como Talian ${ }^{6}$, constando também as denominações: italiano, dialeto, dialeto vêneto, vêneto e vêneto-brasileiro.

De acordo com Wardhaugh (1993, p. 37), coiné é uma forma de fala compartilhada pelas pessoas de diferentes vernáculos ${ }^{7}$.

Já Margotti (2004) assevera que

O dialeto vêneto foi se impondo de forma natural na Região Sul do Brasil. É esse dialeto, aqui modificado pelo contato com outros dialetos italianos, especialmente o lombardo, que dá origem ao talian ou à

\footnotetext{
${ }^{5}$ Excetuou-se deste estudo a colônia de Santa Maria do Novo Tirol, em Piraquara, a qual foi fundada por imigrantes trentinos.

${ }^{6}$ Adotamos, no CEVEP, a nomenclatura Talian, com a consoante oclusiva em maiúscula para dar destaque à língua. No entanto, a escolha do nome Talian não exclui as demais possibilidades também citadas pelos falantes e acima referidas.
}

${ }^{7}$ A form of speech shared by people of different vernaculars (WARDHAUGH,1993, p. 37). 
coiné vêneta (...). Foi essa coiné que se defrontou, na escola e na vida sócio-político-econômica, com o português, falado diversamente nas diferentes regiões. A miscigenação lingüística se deu à semelhança da mistura dos sangues. (MARGOTTI, 2004, p. 38).

Ainda no tocante à colonização italiana no Sul do Brasil e à coiné de base vêneta, Luzzatto (1994) aponta que

\begin{abstract}
dos imigrantes italianos que colonizaram o Sul do Brasil, aproximadamente $95 \%$ eram provenientes do Vêneto, do Trentino-Alto Ádige, do Friuli-Venezia Giulia, isto é, do Tri-Vêneto, e da Lombardia. Desses imigrantes, mais de $60 \%$ possuíam a língua e a cultura vênetas. Tinham falares diferentes, sotaques distintos, mas a língua-mãe era a mesma: o vêneto. Quando aqui chegaram foram instalados em colônias, sem respeitar a origem de cada família. Assim, uma família trentina da Valsugana, por exemplo, passava a ser vizinha de uma friulana, de Pordenome, de um lado, e de outra lombarda, de Bérgamo, com várias famílias vênetas ao seu redor. Evidentemente era preciso entender-se. Daí resultou uma língua de comunicação, uma coiné, muito mais vêneta do que lombarda, ou friulana, ou trentina, pois vêneta era a maioria (LUZZATTO, 1994, p. 21-23).
\end{abstract}

Em relação à manutenção das referências culturais na região pesquisada, pontuamos que embora alguns dos antigos núcleos coloniais hoje sejam localizados em áreas urbanizadas da cidade de Curitiba (o bairro de Santa Felicidade) e da sua região metropolitana (o bairro da Rondinha em Campo Largo e o centro de Colombo), notamos que as comunidades italianas ainda mantêm elementos e traços da cultura dos imigrantes, os quais identificamos nos seguintes aspectos:

- na religiosidade expressa na arquitetura das igrejas e na presença marcante do catolicismo na vida social dos descendentes, nos santos de devoção (Nossa Senhora de Monte Bérico, de Caravaggio, San Bovo, Santo Antônio, etc) e nas missas em língua italiana e em Talian;

- nas famílias e sobrenomes tradicionais, cujas relações de parentesco e memórias se entrelaçam com muitos membros das antigas colônias e das cidades nos arredores;

- nos ofícios tradicionais, como o trabalho do vime de Santa Felicidade, a porcelana de Campo Largo, o cultivo da uva em Colombo e a vinificação;

- nos hábitos alimentares dos descendentes das colônias italianas, baseada, principalmente, na polenta feita de fubá de milho branco, que é típica de determinadas áreas do Vêneto; 
- na gastronomia do bairro de Santa Felicidade, que é um polo gastronômico reconhecido em nível nacional e internacional;

- nas festividades como as Festas da Uva de Santa Felicidade e de Colombo, as semanas italianas de Colombo e Campo Largo, os aniversários das colônias e a Festa da Polenta, do Frango e do Vinho de Santa Felicidade;

- nas associações locais como o Circolo Vicentini nel Mondo, a Associação Italiana Padre Alberto Casavecchia e a Associazione Veneti nel Mondo Colombo;

- nos grupos foclóricos, corais e grupos musicais, como os grupos ÍtaloBrasileiro e Giardino d'amuri (Santa Felicidade), Piccola Italia (Campo Largo) e Luce dell'anima (Colombo);

- e, finalmente, na língua Talian que permeia todos os aspectos culturais acima citados e que está presente, especialmente entre os mais idosos, no interior dos lares, no trabalho e em determinados espaços sociais (igrejas e clubes esportivos, principalmente).

\section{PRINCIPAIS AÇÕES DO CEVEP}

Conforme já destacado, o $\mathrm{CEVEP}^{8}$ é formado por pesquisadores de universidades (UNICENTRO, UFPR, PUC-PR), do Instituto do Patrimônio Histórico e Artístico Nacional, IPHAN, do Museu Municipal Cristòforo Colombo, da Associazione Veneti nel Mondo e de membros da comunidade de ítalo descendentes do bairro de Santa Felicidade, em Curitiba, e dos municípios de Colombo, Campo Largo e Lapa, no Paraná.

Entre as principais ações que estão sendo desenvolvidas pela equipe do CEVEP vamos apresentar, neste texto, $(i)$ como se deu a constituição do Banco de Dados do Talian; (ii) uma pequena amostra da elaboração de glossários com registros das variedades de Talian faladas em cada comunidade pesquisada; (iii) uma síntese da elaboração de material didático em Talian; (iv) em que consiste a coleta e digitalização de material escrito de descendentes de italianos (vênetos) e em (v) apresentamos algumas ações em prol da cooficialização do Talian no Paraná.

Dessa forma, objetivamos valorizar e promover parte dessa diversidade linguística evidenciada em nosso entorno e, também, estimular novos pesquisadores a trabalharem em prol da diversidade linguística e cultural que é tão presente em nosso país.

\footnotetext{
${ }^{8}$ Grupo cadastrado na Plataforma do CNPq, vide <http://dgp.cnpq.br/dgp/espelhogrupo/41028 49645045565>. Acesso em 10 jul. 2020.
} 


\section{Banco de Dados do Talian}

Em 2018 parte da equipe ${ }^{9}$ do CEVEP deu início à coleta de dados de falantes de Talian de Colombo e de Santa Felicidade. A partir de 2019, Campo Largo também foi incluída na coleta. Atualmente já temos 40 entrevistas realizadas em Santa Felicidade; 32 em Colombo e 04 entrevistas em Campo Largo. A equipe objetiva coletar de 30 a 50 entrevistas em cada comunidade pesquisada e os falantes são estratificados ${ }^{10}$ pelas variáveis sexo e etnia.

Para a montagem do Banco de Dados do Talian, adotamos os pressupostos teóricometodológicos da Teoria da Variação e Mudança (TVM) ou Sociolinguística Quantitativa (ou Laboviana). Segundo Weinreich, Labov e Herzog, 2006 [1968], a teoria nasceu em um momento sócio-histórico em que a Linguística havia sido inicialmente dominada pelas ideias de Saussure (início do século XX) e, mais tarde, por Chomsky (por volta dos anos 60 do século XX). Tanto Saussure quanto Chomsky, no entanto, privilegiaram os estudos linguísticos voltados aos fatos internos das línguas. Já os estudos de Labov (e da Sociolinguística) não se situam à margem de uma linguística da língua, uma vez que ele considera que esta só tem sentido no contexto social.

Labov (2008 [1972]) afirma que um dos pressupostos básicos da TVM é o de que a heterogeneidade é inerente a todas as línguas e variedades e que tal heterogeneidade é ordenada, regrada. Ou seja, a variação não é aleatória, pois apresenta restrições de natureza linguística e social. Tais restrições fazem com que o falante, embora inconscientemente na maioria das vezes, utilize de certas formas em detrimento de outras. Naro (2013) apresenta a questão da heterogeneidade versus homogeneidade da língua da seguinte forma,

o pressuposto básico do estudo da variação no uso da língua é o de que a heterogeneidade linguística, tal como a homogeneidade, não é aleatória, mas regulada, governada por um conjunto de regras. Em outras palavras, tal como existem condições ou regras categóricas que

\footnotetext{
${ }^{9}$ Os integrantes do grupo se subdividem em frentes de trabalho e uma das frentes se dedica à coleta de entrevistas sociolinguísticas.

${ }^{10}$ A estratificação dos falantes do Banco de Dados do Talian não abarca as variáveis sociais escolaridade e faixa etária, normalmente contempladas em bancos de entrevistas sociolinguísticas em língua portuguesa, em função da especificidade do nosso banco, cujas entrevistas são na língua de herança. Há também poucas entrevistas, geralmente de falantes jovens, em que o entrevistador fala em Talian e o entrevistado responde em português. Contudo, o foco consiste em ambos (entrevistador e entrevistado) falarem Talian durante toda a entrevista.
} 
obrigam o falante a usar certas formas (a casa) e não outras (casa a), também existem condições ou regras mudáveis que funcionam para favorecer ou desfavorecer, variavelmente e com pesos específicos, o uso de uma ou outra das formas em cada contexto. (NARO, 2013, p. $15)$.

Ou seja, conforme exemplificado por Naro, tanto a homogeneidade quanto a heterogeneidade são ordenadas e fazem parte das línguas naturais. Isto porque nem tudo varia e muda na língua com o tempo, assim como nem tudo é categórico. Nota-se, portanto, que há nas línguas vivas um processo constante e regrado de renovação.

Dessa forma, no CEVEP, para registrar o Talian falado pelos detentores e posterior descrição e análise de sua heterogeneidade, da explicitação das variantes utilizadas em cada comunidade, bem como das variáveis linguísticas e sociais que atuam na estrutura do Talian, a abordagem teórico-metodológica não poderia ser outra, senão a TVM. Optamos pela coleta de entrevistas sociolinguísticas faladas em Talian, pois o objetivo é, em um primeiro momento, termos o registro efetivo (via narrativas de experiência pessoal com áudio de boa qualidade sonora e com gravações de, no mínimo, 40 minutos de fala cada), dessa língua de herança nas comunidades pesquisadas.

Em relação ao perfil dos entrevistados, foram definidos três critérios básicos: $(i)$ Falantes descendentes de italianos (ou seja, ser descendente de italiano por parte de pai ou de mãe, ou de ambos); (ii) Ter contato com a cultura do italodescendente e conhecimento do Talian (pelo menos no nível da oralidade) e (iii) Ter nascido na comunidade pesquisada e/ou ter se mudado para lá no máximo aos 2 anos de idade. O critério (ii), no entanto, se sobressai aos demais nas escolhas dos entrevistados. Isto porque, ao entendermos o Talian das comunidades pesquisadas como língua de herança, e conforme já devidamente apontado na nota 1 , é fundamental que haja identificação cultural e sentimento de pertencimento à comunidade (cf. ORTALE, 2016) para que o entrevistado seja selecionado. Para tanto, a atuação de líderes ${ }^{11}$ locais é fundamental neste processo.

Definidos os critérios em relação ao perfil dos entrevistados, o próximo passo consistiu na montagem da Ficha Social, instrumento que visa a facilitar a coleta de dados, uma vez que fornece a confirmação do perfil social do entrevistado. Para dar conta disso, a ficha contempla questões que versam sobre $(i)$ histórico familiar (origem étnica e geográfica; membros e suas ocupações; línguas que falam ou entendem); (ii) histórico

\footnotetext{
${ }^{11}$ No CEVEP há integrantes de todas as comunidades pesquisadas, detentores do Talian, que são líderes comunitários e participam ativamente, por exemplo, de associações ligadas ao Talian; de grupos ligados às igrejas, às missas, à catequese; às semanas italianas etc.
} 
pessoal (ano de nascimento; escolarização; profissão atual e as que já teve; viagens e mudanças); (iii) rede de relações (exposição a rádio; TV; jornais; participação na igreja local) etc.

Outro ponto que mereceu a atenção dos pesquisadores do CEVEP está relacionado à elaboração do roteiro de perguntas. Tal roteiro é composto por um rol de perguntas voltadas ao dia a dia do falante, priorizando as narrativas de experiência pessoal. Na visão de Tarallo (1990),

Os estudos de narrativas têm demonstrado que, ao relatá-las, o informante está tão envolvido emocionalmente com o que relata que presta o mínimo de atenção ao como. E é precisamente esta a situação natural de comunicação almejada pelo pesquisador-sociolingüista. (TARALLO, 1990, p. 22).

O roteiro objetiva facilitar a comparação de dados de vários informantes por meio do controle dos tópicos da conversação. De acordo com o perfil social do entrevistado, há uma série de tópicos que facilitam a conversação. Tarallo (1990, p. 22) afirma que é preciso considerar

os dados pessoais do informante [sua história], jogos e brincadeiras de infância, brigas, namoro e encontros amorosos, casamento, perigo de morte, medo, família, religião, amigos, turmas, serviços públicos, o crime nas ruas, escola e trabalho, interação com outros membros da comunidade, esportes, etc.

Estes tópicos irão variar em cada comunidade pesquisada e até mesmo dependendo de cada indivíduo entrevistado. Isto porque o roteiro serve como um guia que pode ser flexibilizado a depender do entrevistado e de sua história de vida. Cabe ao pesquisador conhecer a comunidade a ser pesquisada, o histórico da localidade e o perfil do informante a ser entrevistado, pois esse conhecimento prévio poderá ser decisivo para o sucesso da entrevista. No entanto, de nossa experiência de coleta ${ }^{12}$, o fundamental é o pesquisador se mostrar interessado em conhecer as histórias contadas pelo falante.

Nas entrevistas sociolinguísticas já realizadas com moradores das cidades

\footnotetext{
${ }^{12}$ A pesquisadora que coordena a equipe tem mais de 30 anos de experiência em coleta de dados sociolinguísticos. Atuou como bolsista de Iniciação Científica na coleta, transcrição, revisão e análise de entrevistas do Projeto VARSUL/UFSC. É também uma das idealizadoras e coordenadoras do Banco Variação Linguística de Fala Eslava, VARLINFE, pertencente ao Núcleo de Estudos Eslavos, NEES, da Unicentro.
} 
de Colombo, Campo Largo e do bairro de Santa Felicidade em Curitiba, seguimos as especificações relatadas acima e que são frequentes nas coletas de dados sociolinguísticos. Observamos que há um número significativo de falantes do Talian nas comunidades pesquisadas, bem como de praticantes dos costumes trazidos pelos seus antepassados. Isso tudo foi explorado por meio do Roteiro de Perguntas.

De modo geral, percebeu-se que por muito tempo os detentores dessa língua/ cultura sentiram-se inferiores, viveram preconceitos e constrangimentos por, segundo eles, falarem com sotaque. Com o intuito de promover o respeito linguístico, de valorizar os diferentes modos de falar e proporcionar uma visão não discriminatória, seja de qualquer tipo de preconceito, o CEVEP procura promover e valorizar iniciativas voltadas às comunidades de falantes do Talian. Ou seja, além da coletas de entrevistas sociolinguísticas são feitas também devolutivas constantes às comunidades. Podemos citar como exemplo: o Encontro ${ }^{13}$ dos Difusores do Talian; a noite do Talian em Colombo; um Dia no Museu Municipal Cristòforo Colombo, entre outras atividades plurais de natureza sociolinguística que considerem a "comunidade social sob seu aspecto linguístico" (CALVET, 2002, p. 127). Dessa forma, também se está aproximando o meio acadêmico aos falantes/detentores da língua e devolvendo à comunidade parte do que ela proporciona à sociedade e à academia.

\section{Elaboração de glossários/dicionários (com registros das variedades de Talian fala- das em cada comunidade pesquisada).}

A equipe do CEVEP que trabalha nessa frente visa organizar, aproximadamente, quatro mil lexias em Língua Talian falada em Curitiba e região metropolitana. Inicialmente o levantamento e a catalogação estão sendo realizados no bairro de Santa Felicidade e na cidade de Colombo. O objetivo é efetuar o registro das variedades de Talian faladas em cada comunidade pesquisada.

A catalogação do corpus lexical tem como base o acervo de entrevistas sociolinguísticas; listas de palavras pessoais e a análise de materiais escritos produzidos na região já especificada. O corpus final foi aperfeiçoado e nele foram anexadas mais lexias resultantes da colaboração de integrantes do CEVEP. Ao analisar as lexias das duas localidades citadas, a equipe percebeu que há muitas equivalências do ponto de vista do

\footnotetext{
${ }^{13}$ O Encontro já está em sua XXIV edição e em 2021 está sendo organizado pela equipe do CEVEP e se realizará em Colombo, PR. Tradicionalmente, a Associação dos Difusores do Talian, ASSODITA, é a idealizadora e mantenedora do evento.
} 
significado e do uso, mas há algumas diferenças do ponto de vista fonético como, por exemplo, as variantes para a palavra amarela: dala (em Santa Felicidade) e daea (em Colombo). Tais variantes passaram, então, a serem especificadas na proposta de dicionário com a devida especificação da comunidade em que a variante é produzida.

Com isso, vai-se registrar o uso real das formas de acordo com cada comunidade pesquisada e se terá o registro das variantes locais do Talian. O material servirá de base para o trabalho de valorização do multilinguismo e da promoção da diversidade linguística. Vai-se também evidenciar um dos postulados da Sociolinguística Laboviana de que as comunidades de fala são heterogêneas, que não há homogeneidade linguística nem dentro de uma mesma língua, e que os falantes-ouvintes reais não se expressam da mesma maneira em diferentes situações de comunicação. É essa heterogeneidade ordenada que se busca registrar nas entrevistas e descrever nos glossários/dicionários.

\section{Elaboração de material didático/ensino do Talian}

Outra frente de trabalho do CEVEP tem-se dedicado à elaboração de material didático voltado ao ensino e à conscientização sociolinguística do Talian.

A proposta da equipe é produzir o material didático a partir de dados provenientes dos próprios detentores dessa língua, moradores das comunidades pesquisadas no Paraná (até então, Santa Felicidade, Colombo e Campo Largo). Ou seja, áudio, vídeos e imagens são feitos pelos próprios falantes e devidamente autorizados para serem utilizados no material didático. Além disso, o material se propõe a explorar mais a oralidade que a escrita e também apresenta e mostra a importância de se respeitar as diferentes variedades do Talian no Paraná.

O material produzido é uma ferramenta para que professores (falantes ou não) possam utilizá-lo em aulas de línguas. Como fundamentação teórica para a elaboração do material didático, a equipe entende o Talian como língua de herança (ORTALE, 2016), e segue a metodologia baseada em tarefas (cf. SANTOS, 2014 e ELLIS, 2003).

\section{Coleta e digitalização de material escrito de descendentes de italianos (vênetos)}

Tendo como base os trabalhos produzidos no projeto Para a História do Português do Brasil em Santa Catarina, $\mathrm{PHPB} / \mathrm{SC}^{14}$, parte da equipe do CEVEP está coletando

\footnotetext{
${ }^{14}$ O projeto PHPB-SC, coordenado pela professora Izete Lehmkuhl Coelho (UFSC), tem como objetivo (i) levantar e catalogar documentos de diferentes gêneros textuais (cartas ao redator,
} 
materiais escritos dos séculos XIX e XX de descendentes de italianos de Curitiba e região metropolitana.

A abordagem teórico-metodológica utilizada pelo PHPB-SC e pela equipe do CEVEP, para a coleta de material escrito, é a Sociolinguística Histórica, (cf. CONDE SILVESTRE, 2007). Tal abordagem tem como fundamentos básicos alguns pressupostos essenciais da Teoria da Variação e da Mudança Linguística (cf. WEINREICH; LABOV; HERZOG, 2006 [1968]), quais sejam, (i) a variação é inerente ao sistema linguístico; (ii) o uso normal da língua apresenta variedade estruturada; (iii) a mudança linguística é lenta e gradual; (iv) fatores linguísticos e sociais apresentam forte correlação entre si e ( $v$ ) os métodos quantitativos podem ajudar a explicitar e a explicar a variação e a mudança nas línguas.

De acordo com Conde Silvestre (2007), o contato linguístico é um dos âmbitos de investigação da Sociolinguística mais frutíferos das últimas décadas, tanto na vertente sincrônica quanto na diacrônica. Já Aguilera e Busse (2008) apontam que os estudos sobre as línguas em contato

têm suscitado interesse por parte de pesquisadores da área da linguagem, especialmente da sociolingüística, por constituírem material potencial para a descrição e a compreensão das várias instâncias que atuam nos processos de interação, quais sejam lingüísticas, sociais, históricas, psicológicas, entre outras. O motivo pelo qual estudiosos têm se dedicado às investigações de comunidades e falantes bilíngües está representado na possibilidade de compreender o uso da língua como elemento desencadeador de ambientes particulares de interação, governados pela necessidade de comunicação e pela constituição de identidades, em que se podem compreender as várias facetas do modus operandi das línguas. (...) O estudo do contato lingüístico e dos fenômenos lingüísticos decorrentes desta realidade sociocultural movese no interior das teorias da variação lingüística, entendidos como decorrentes de fatores inerentes à condição humana. (AGUILERA e BUSSE, 2008, p. 12).

Os documentos escritos podem conter reflexos do contato linguístico, de forma especial as cartas pessoais, haja vista que são gêneros que apresentam na escrita intercâmbios comunicativos típicos da comunicação oral. É neste tipo de texto escrito

anúncios e cartas pessoais) de quatro regiões catarinenses (Florianópolis, Lages, Chapecó e Blumenau); (ii) editar e disponibilizar os documentos levantados e catalogados à comunidade científica; e (iii) descrever a história social e linguística do português escrito nessas regiões de Santa Catarina, nos últimos dois séculos. 
que se vai encontrar uma recorrência maior de variação e de marcas do vernáculo de diferentes épocas. Ou seja, quando se monta um banco de dados de material escrito de épocas diferentes se está propiciando análises sociolinguísticas, cujo foco consiste em visualizar o passado com as lentes do presente. Também é possível que ocorra a reconstrução dos contextos sociais do passado, por meio da análise das circunstâncias pessoais que se refletem na relação entre os remetentes das cartas e seus destinatários, bem como a partir dos diferentes estilos refletidos nos documentos históricos.

No Paraná já temos no acervo do CEVEP algum material escrito em Italiano e em Talian. A coleta ${ }^{15}$ em português estava prevista para ocorrer em 2020 e se daria diretamente com os detentores do Talian; em igrejas, museus e associações italianas, bem como no Arquivo Público do Paraná. Futuramente objetiva-se catalogar, editar e analisar o material coletado para contribuir com a descrição da história linguística do Talian, do Português e do Italiano e verificar os indícios de contato linguístico na escrita desses três idiomas. Em Santa Catarina a equipe do PHPB coletou material escrito em língua portuguesa e já está em fase adiantada de catalogação e análise ${ }^{16}$. As ações voltadas a essa frente, no entanto, no CEVEP, estão ainda em seu início, sofrerão ajustes, ampliações e irão perdurar por um longo período.

\section{Ações em prol da cooficialização do Talian no Paraná}

Tendo como base as ações de reconhecimento do Talian em alguns municípios gaúchos (Antônio Prado, Bento Gonçalves, Caxias do Sul, Ivorá, Serafina Corrêa, entre outras) e catarinenses (Nova Erechim), a equipe do CEVEP iniciou também algumas discussões em suas reuniões mensais para a cooficialização do Talian no município de Colombo, no Paraná. Neste Estado, até o presente momento não há nenhuma localidade que tenha sido reconhecida com a cooficialização dessa língua no município.

O objetivo da ação proposta é o de valorizar a língua Talian nos meios oficiais e políticos do município, a fim de dar espaço a projetos relacionados à língua de herança

\footnotetext{
${ }^{15}$ Devido ao isolamento social, necessário para se evitar o contágio em massa do covid-19, a coleta de dados teve de ser adiada por tempo indeterminado. Passada a fase de isolamento, no entanto, o acervo desta frente de trabalho será revisto e ampliado com a inclusão de vários tipos de documentos escritos dos descendentes de italianos que possam interessar não apenas à área da Linguística, mas também à Educação, à História, à Arquitetura e às Artes em geral. Com isso, a abordagem teórico-metodológica utilizada também irá sofrer ampliações.

${ }^{16}$ Uma das produções do PHPB-SC, a sair, é o livro organizado por Coelho et al. (Editora da UFSC, no prelo).
} 
no âmbito das políticas municipais de educação. Para isso, realizamos reuniões com políticos locais (vereadores, prefeitos, representantes da comunidade) e com deputados para introduzir e apresentar o tema.

Até o momento, temos em curso um projeto de lei, em parceria com o Museu Municipal Cristòforo Colombo e com a Prefeitura Municipal de Colombo, para tornar a cidade de Colombo a capital paranaense do Talian. As demais ações elencadas em (i) a (iv), no entanto, também servirão de base para que a cooficialização do Talian possa se efetivar em pelo menos um município do Paraná.

\section{CONSIDERAÇÕES FINAIS}

Conforme destacamos ao longo do texto, o Talian foi reconhecido como língua de Referência Cultural Brasileira em 2014, por meio do Inventário Nacional da Diversidade Linguística, e é difundido pelas comunidades tradicionais dos detentores e também pelos meios de comunicação, especialmente o rádio. Ultimamente tem se verificado também um certo predomínio de páginas ${ }^{17}$ em redes sociais (com um vasto número de acessos) que divulgam ações diversas voltadas à língua e à cultura Talian. No entanto, o reconhecimento da importância dessa língua ainda precisa ser trabalhado nas comunidades detentoras e na sociedade em geral.

Nesse cenário, as ações do CEVEP se mostram altamente necessárias para a salvaguarda da língua por meio de atividades de interação com a comunidade detentora; de ações de identificação e registro da língua falada; de análises e publicações que dão visibilidade à língua no contexto nacional e internacional; bem como de ações de sensibilização para a importância do tema junto a agentes públicos e políticos.

Uma das formas de dar visibilidade à língua e à cultura do Talian que a equipe do CEVEP disponibiliza à comunidade mundial é a página ${ }^{18}$ Talian: léngua e cultura. Nela se apresentam e retratam diversos aspectos da variabilidade da língua e aspectos culturais importantes relacionados, principalmente, às comunidades pesquisadas.

Tais ações reverberam, entre outros, também este postulado da Sociolinguística, que Coelho etal (2012,p. 153)o apresentam desta forma: "que todas as variedades sãoigualmente

\footnotetext{
${ }^{17}$ Algumas ações voltadas à língua e à cultura Talian têm tido bastante repercussão no isolamento social, especialmente as lives. Diversos grupos e associações que já vinham desenvolvendo um trabalho presencial efetivo com as comunidades de detentores passaram a utilizar o ambiente virtual para não interromper o trabalho que vinha sendo desenvolvido.
}

${ }^{18}$ Disponível em: <https://www.facebook.com/talianlenguaecultura/>. Acesso em 01 jun. 2020. 
bem estruturadas, sendo mais ou menos adequadas a determinadas situações comunicativas. As avaliações das formas linguísticas - como sendo de prestígio ou estigmatizadas são de natureza social e não linguística, sendo carregadas de preconceito linguístico." Para tanto, conforme sabiamente aponta Scherre (no prelo), o respeito linguístico é fundamental, haja vista que "as diferenças linguísticas, em qualquer plano, incluindo o social, caracterizam grupos de falantes e são mecanismos identitários."

Logo, com base nos postulados da Sociolinguística, a equipe do CEVEP tem procurado atuar com ações concretas para o registro, descrição, análise, ensino; para a promoção do respeito linguístico, demostrando que o Talian é uma língua estruturada, sujeita a variações e mudanças como ocorre a toda língua natural. A partir disso, o caminho para a cooficialização e conscientização sociolinguística da importância dessa língua de herança às comunidades pesquisadas e à sociedade em geral será menos árduo. 


\section{REFERÊNCIAS:}

AGUILERA, V. de A.; BUSSE, S. Contato lingüístico e bilingüismo: algumas reflexões para o estudo do fenômeno da variação lingüística. Revista Línguas \& Letras, Cascavel, v. 9 , n. $16,1^{\circ}$. Sem. 2008. p. 11-25.

BALHANA, A. P. Santa Felicidade: um processo de assimilação. Curitiba: J. Haupt \& Cia, 1958.

BALHANA, A. P. et al. História do Paraná. Curitiba: Grafipar, 1969.

BALHANA, A. P. Santa Felicidade: Uma Paróquia Vêneta no Brasil. Curitiba: Fundação Cultural de Curitiba, 1978.

CALVET, L. Sociolingüistica: uma introdução crítica. São Paulo: Parábola, 2002.

COELHO, I. L. et al. Sociolinguística. Florianópolis: LLV/CCE/UFSC, 2012.

COELHO, I. L. et al. Aspectos sócio-históricos e linguísticos do português escrito em Santa Catarina nos séculos XIX e XX. Florianópolis: Editora da UFSC (no prelo).

CONDE SILVESTRE, J. C. La Sociolingüística Histórica y el Cambio Lingüístico. In.: CONDE SILVESTRE, J. C. Sociolingüistica histórica. Madrid: Gredos, 2007.

ELLIS, R. Task-based language teaching and learning. Oxford: Oxford University Press, 2003.

LABOV, W. Padrões Sociolingüísticos. Tradução de Marcos Bagno, Maria Marta Pereira Scherre e Caroline Rodrigues Cardoso. São Paulo: Parábola, 2008 [1972].

LUZZATTO, D. L. Talian (vêneto brasileiro): noções de gramática, história; cultura. Porto Alegre: Sagra; D.C. Luzzatto, 1994.

MACHIOSKI, F. L. A preservação da identidade cultural em um grupo imigrante italiano curato de Colombo, Paraná, 1888 - 1910. 87 f. Monografia (Graduação em História) Setor de Ciências Humanas, Letras e Artes, Universidade Federal do Paraná, Curitiba, 2004.

MACHIOSKI, F. L. Uma luta ultramontana: o discurso do padre Pietro Colbacchini e o forjar da identidade dos imigrantes italianos em Curitiba no final do século XIX (1886-1901). 201 p. Dissertação (Mestrado em História) - Setor de Ciências Humanas, Universidade Federal do Paraná, Curitiba, 2018. 
MARGOTTI, F. W. Difusão sócio-geográfica do português em contato com o italiano no sul do Brasil. 332 p. Tese (Doutorado em Letras) - Instituto de Letras, Universidade Federal do Rio Grande do Sul, Porto Alegre, 2004.

MARTINS, R. História do Paraná. Curitiba: Travessa dos Editores, 1995.

MENGARDA, E. J. Gênese e Evolução dos Dialetos Trentino e Vêneto. Working Papers em Lingüistica, Florianópolis, UFSC, v. 1, n. 5, 2001. p. 42-56.

NARO, A. J. Modelos Quantitativos e Tratamento Estatístico. In: MOLLICA, M. C.; BRAGA, M. L. (Orgs.). Introdução à Sociolinguística: O Tratamento da Variação. São Paulo: Contexto, 2013.

ORTALE, F. L. A formação de uma professora de italiano como língua de herança: o pósmétodo como caminho para uma prática docente de autoria. 162 p. Tese (Livre Docente em Língua Italiana) - Faculdade de Filosofia, Letras e Ciências Humanas, Universidade de São Paulo, São Paulo, 2016.

SANTOS, J. M. P. Propostas de critérios para elaboração de unidades temáticas e de enunciados de tarefas em contexto de ensino de PLE no Celin-UFPR. 149 p. Dissertação (Mestrado em Estudos Linguísticos) - Setor de Ciências Humanas, Universidade Federal do Paraná, Curitiba, 2014.

SCARPIM, F. A. Bens simbólicos em laços de pertencimento: família, religiosidade e identidade étnica em um grupo de imigrantes italianos (Campo Largo-PR, 1878-1937). Dissertação (Mestrado em História) - Setor de Ciências Humanas, Universidade Federal do Paraná, Curitiba, 2010.

SCHERRE, M. M. P. RESPEITO LINGUÍSTICO. Dicionário: rumo à civilização da religação e ao bem viver, organizado por ARNT, Rosamaria de Medeiros; SCHERRE, Paula Pereira. Águas Belas: ONG Semente dos Sonhos $<\mathrm{http}: / /$ sementedossonhos.org/wp/>. No prelo.

TALIAN: léngua e cultura. Disponível em: <https://www.facebook.com/talianlengua ecultura/>. Acesso em 01 jun. 2020.

TARALLO, F. A pesquisa sociolingüistica. São Paulo: Ática, 1994.

URSINI, F. Dialetti Veneti, Treccani Enciclopedia, 2011. Disponível em: <http://www. treccani.it/enciclopedia/dialetti-veneti_\%28Enciclopedia-dell\%27Italiano\%29/>. Acesso em 14 jun. 2020. 
WARDHAUGH, R. An introduction to sociolinguistics. Oxford; Cambridge: Blackwell, 1993.

WEINREICH, U.; LABOV, W. e HERZOG, M. Fundamentos empíricos para uma teoria da mudança lingüistica. Tradução de Marcos Bagno. São Paulo: Parábola, 2006 [1968]. 